\title{
Subjectivity and flexibility in invasion terminology: too much of a good thing?
}

\author{
Robert I. Colautti · David M. Richardson
}

Received: 15 July 2008/Accepted: 25 July 2008/Published online: 13 August 2008

(C) Springer Science+Business Media B.V. 2008

\begin{abstract}
Invasions biologists have frequently debated whether the definition of invasive should include ecological and economic impacts. More recent criticisms posit that objective definitions are impossible in any absolute sense, while subjectivity is desirable for its flexibility and motivational qualities. We argue that such criticisms underestimate the extent of subjectivity already present in invasion biology. Ecological questions may be methodological if they relate directly to other ecological theories and models, or motivational if they focus on issues important to society as a whole. Motivational questions are important for engaging scientists, improving public understanding of science, and often have applied benefits. In contrast, methodological questions are constrained by established scientific theories, and are therefore more efficient for the development of scientific knowledge. Contrary to recent critiques, we suggest that greater objectivity is both achievable and desirable for the discipline of invasion biology and ecology generally.
\end{abstract}

R. I. Colautti $(\bowtie)$

Department of Ecology and Evolutionary Biology, University of Toronto, 25 Willcocks St, Toronto, ON, Canada M5S 3B2

e-mail: rob.colautti@utoronto.ca;

colautti@botany.utoronto.ca

D. M. Richardson

Centre for Invasion Biology, Department of Botany and

Zoology, Stellenbosch University, Private Bag X1,

Matieland 7602, South Africa

e-mail: rich@sun.ac.za
Keywords Invasive species - Methodological questions - Motivational subjectivity ·

Terminology $\cdot$ Objective definitions

Terminology can have a profound influence on scientific thought and discovery. This is why international standards are common among professional science organizations, and science textbooks regularly include glossaries of common terms. Scientists occasionally attempt to clarify terminology in their discipline and this is particularly true for invasion biology, where definitions of invasive, naturalized or alien have been debated frequently (e.g. Davis and Thompson 2000; Richardson et al. 2000, 2008; Daehler 2001; Rejmánek et al. 2002; Colautti and MacIsaac 2004; Pyšek et al. 2004; Colautti 2005; Warren 2007; Valéry et al. in press). But attempts to clarify or unify ecological terminology have been criticized recently, mainly over concerns about the inevitability of subjectivity in scientific research, the impossibility of a formalized scientific method or lexicon, and the importance of flexible terminology for communicating scientific issues (e.g. Larson 2007; Hodges 2008).

Issues involving terminology may benefit from the input of researchers, like Larson (2007) and Hodges (2008), who are well-versed in the philosophies of science, language, and policy. The positive role of subjectivity and flexible terminology in science generally has been argued elsewhere (e.g. Kuhn 1962; Feyerabend 1993), while its negative effects are 
evident in public controversies surrounding the science of climate change or the merits of intelligent design (e.g. Bykoff 2008; Forrest and Gross 2004). However, we are concerned that our arguments for more objectivity in invasion terminology have been misrepresented as an extreme form of logical empiricism and used as a straw-man to critique a constrictive view of scientific communication. Using examples from invasion biology, we argue that the views expressed by Larson (2007); Hodges (2008) underestimate the level, and confuse the type of subjectivity that currently underpins several ecological terms and concepts, much to the detriment of the field. Notwithstanding the potential importance of some level of subjectivity for science in general, we here try to clarify our argument for the merits of greater objectivity and consensus in terminology associated with biological invasions and why we believe it will improve the science of invasion biology. Although we have focused our critique on the study of biological invasions, parallels can easily be drawn to other attempts to formalize ecological concepts (e.g. biodiversity, ecosystem, ecosystem engineer, habitat, keystone).

The criticisms presented by Hodges (2008) are aimed at attempts to unify terminology in ecological research generally, focusing on the importance of flexibility - a useful form of subjectivity - in concepts and definitions. Specifically, Hodges (2008) argues that (i) flexible terminology stimulates the generation of knowledge, and (ii) clarifying and standardizing ecological terminology impedes research by closing areas of inquiry. Larson (2007) is more specific in criticizing the terminology proposed by Colautti and MacIsaac (2004; hereafter C\&M), as follows. First, attempts to standardize terminology assume a false dichotomy between facts and values, and are thereby flawed because no science can be objective in an absolute sense. Second, C\&M fail to acknowledge that facts cannot be independent of human perception. Since subjectivity is inevitable in science, the C\&M model cannot be considered objective. Finally, the $\mathrm{C} \& \mathrm{M}$ model ignores the importance of subjectivity for motivating scientists and facilitating public discourse. Contrary to these perspectives, we argue that the key issue is not whether terminology pertaining to invasive species can (or should) be objective or standardized in any absolute sense, but rather whether it can be clarified and made more objective, and whether this would improve the science of invasion biology.
We suggest that paths of scientific inquiry come in different forms, which we will term methodological and motivational for the purpose of this discussion. Table 1 demonstrates the difference between methodological and motivational questions using examples from invasion biology. Though not taken from any particular study, we think these questions exemplify common questions explicit or implicit in the current literature on biological invasions, with obvious parallels to other ecological disciplines. Subjectivity and flexibility associated with methodological questions (hereafter methodological subjectivity) arise as an inevitability of the desire for generality in science, but are constrained because questions are linked to wellestablished scientific theories and paradigms. For example, most ecologists would immediately associate "rate of population growth" in question \#2 (Set A) with $r$, the intrinsic rate of growth, which has a long history in ecology and a solid theoretical basis (e.g. Richards 1959). The question then becomes: "what is the best way to measure $r$," rather than: "what is population growth rate?" There is some flexibility in how one might define the rate of growth for their

Table 1 Two sets of scientific questions, common in invasion biology, which demonstrate different levels of subjectivity

Set A: Methodological questions

1. What factors determine whether an introduced species establishes?

2. What affects the rate of population growth in introduced species and does it differ from natives?

3. Why do some introduced species spread faster than others?

4. How does propagule pressure affect the population genetics of introduced species?

5. How do native herbivores affect the fitness of introduced species?

Set B: Motivational questions

6. How important are invasive species relative to other environmental issues?

7. Which species will have a negative impact?

8 . Why should we be concerned about invasive species?

9. Should we allow species $\mathrm{X}$ or $\mathrm{Y}$ into the country?

10. What is the best way to control invasive species $Z$ ?

Questions in Set A may not be strictly objective because different researchers studying different species in different habitats will use different criteria to measure self-sustaining or rate of population growth or spread. However, these judgements are constrained by ecological and evolutionary theory, while the subjectivity inherent in terms from Set B, like environmental issues or impact or concern, are not 
particular taxon or study system, but limiting definitions to those based on well-established ecological theory improves communication with other scientists, allows more directed hypothesis testing, and reduces the potential for bias.

In contrast, motivational subjectivity is poorly constrained by scientific theory, thereby obscuring biological process in favour of flexibility to motivate scientific research and engage the public. For example, the term impact from question \#7 (Set B) is not clearly associated with any specific ecological or evolutionary processes (Williamson 2001), and thus includes both methodological subjectivity and the values held by society as a whole (Lodge et al. 2006). We suggest that this is a crucial motivation for excluding any connotation of impact in any criteria for a biological definition of invasive (see Richardson et al. 2000, 2008; Daehler 2001; Rejmánek et al. 2002; but see Davis and Thompson 2000, 2001 for counterarguments). When we argue for greater objectivity in invasion biology, we are (i) advocating a reduction in motivational subjectivity in scientific research, without dismissing its importance for public education as a whole, and (ii) implicitly allowing for methodological subjectivity-a limited form of flexibility in definition.

Motivational subjectivity can be an important component of public discourses in science, and this may be the type of subjectivity Larson (2007) had in mind when he noted its importance for improving public understanding of science. For example, the notion of the ecological and economic impact of an introduced species incorporates societal values and therefore might be an enticing criterion for the definition of an invasive species (see Davis and Thompson 2001). Incorporating societal values can be a powerful method for inspiring research programmes and engaging the public. This explains why impact has been included as a criterion for invasive species in public policy issues (e.g. Executive Order 13112 on Invasive Species, February 3, 1999), despite objections by many ecologists (see Richardson et al. 2000, 2008; Daehler 2001; Rejmánek et al. 2002).

Including highly subjective concepts, like impact, as a criterion in discourse among professional scientists-in peer-reviewed publications for example-only serves to obscure scientific understanding of the ecological and evolutionary processes underlying the invasion process. In particular, it has been shown that the rates of establishment and spread of an introduced species are not correlated with its demonstrated impacts, at least partially as a result of difficulties inherent in quantifying impacts in the first place (Parker et al. 1999; Ricciardi and Cohen 2007). Because there is no firm basis in ecological theory, virtually any measure of impact can be used to call a species invasive, making generalizations difficult, or even spurious. It should not be surprising that generalities are absent, and contradictory results common, in the most active areas of invasion biology research: characteristics of successful invaders, enemy release hypothesis, evolution of increased competitive ability, and habitat susceptibility, for example. Loose definitions therefore do impede diffusion of scientific ideas and impede research efficiency, contrary to Hodges' (2008) argument. It is precisely this disconnect of invasive in the ecological from the public policy senses, and the inconsistent definition in scientific publications, that motivated our original attempts to clarify invasion terminology (Richardson et al. 2000; Colautti and MacIsaac 2004).

Whether one wishes to use the example of subjectivity vs. objectivity, flexibility vs. clarity, or motivational vs. methodological, we believe it is clear that subjectivity of terms in many disciplines of ecology can and should be reduced when communicating research among biologists. Referring to an introduced species as invasive because it has an ecological or economic impact adds a level of subjectivity that removes invasive from established ecological and evolutionary theory. Examples of confused terminology that were reviewed in Richardson et al. (2000), and the inconsistent inclusion of impact to define invasive species are therefore more than "... a few anecdotes of genuine confusion where authors conflated dissimilar observations..." (Hodges 2008; p. 36).

Despite the importance of clear terms and consistent definitions among researchers, our entire argument is moot if terminology cannot be clarified. Hodges (2008; p. 39) identifies three reasons why attempts to standardize ecological terminology are likely to fail: (i) everyone must agree on the same definition, (ii) older publications will remind readers of previous meanings, and (iii) new meanings will creep in to all but the most concisely defined terms. 
Although not acknowledged by Hodges (2008), the C\&M framework explicitly addressed these issues by advocating a set of supplementary terms to clarify invasion terminology, while still retaining some flexibility. Because it is grounded in biogeography, the $\mathrm{C} \& \mathrm{M}$ model and its predecessors eliminate motivational subjectivity but allow enough methodological subjectivity to avoid the problems that Larson (2007); Hodges (2008) raise.

Our example of motivational and methodological subjectivity may represent an artificial dichotomy. Nevertheless, it demonstrates how unrestrained flexibility of definitions and subjectivity of method, such as the indiscriminate adoption of societal values into scientific terms and definitions in primary research articles, is less efficient for the advancement of scientific theory. The arguments of Larson (2007) and Hodges (2008) support a research programme in invasion biology that could be harmful to scientific understanding because they underestimate the level of subjectivity already present in many disciplines of ecology. We wish to stress that we are acutely aware of the importance of public engagement in the scientific process (Richardson et al. 2008). Our own research, and that of many other invasion biologists, includes the formulation of management strategies and policy recommendations (e.g. Colautti et al. 2006; Foxcroft et al. 2008; van Wilgen et al. 2008). Without compromising the need for more objectivity in invasion biology, these exemplify Larson's assertion that "...scientists need to interact with nonscientists to conduct research that is of value to society" (Larson 2007; p. 952). While we agree that communication between scientists and the rest of society is imperative, we caution against the careless incorporation of motivational subjectivity into the methods of science, particularly in peer-reviewed publications (see also Richardson et al. 2008). As scientists, invasion biologists can best serve society if we allow motivational subjectivity into public discourse but attempt to minimize it in the methods of scientific inquiry.

Acknowledgements We are grateful to $\mathrm{S}$. Barrett, S. Yakimowski, A. Colautti, J. Wilson and S. Ganjbakhsh for feedback on early drafts of this paper. Our research is supported by an Ontario Graduate Scholarship to R. Colautti and funding from the DST-NRF Centre of Excellence for Invasion Biology and the Hans Sigrist Foundation to D. Richardson.

\section{References}

Bykoff MT (2008) Lost in translation? United States television news coverage of anthropogenic climate change 19952004. Clim Change 86:1-11. doi:10.1007/s10584-0079299-3

Colautti RI (2005) In search of an operational lexicon for biological invasions. In: Inderjit (ed) Invasive plants: ecological and agricultural aspects. Birkhauser, Basel, pp 1-15

Colautti RI, MacIsaac HJ (2004) A neutral terminology to define 'invasive' species. Divers Distrib 10:135-141. doi: 10.1111/j.1366-9516.2004.00061.x

Colautti RI, Bailey SA, van Overdijk CDA, Admunsen K, MacIsaac HJ (2006) Characterised and projected costs of nonindigenous species in Canada. Biol Invasions 8:45-59. doi:10.1007/s10530-005-0236-y

Daehler CC (2001) Two ways to be an invader, but one is more suitable for ecology. ESA Bull 82:101-102

Davis MA, Thompson K (2000) Eight ways to be a colonizer; two ways to be an invader: a proposed nomenclature scheme for invasion ecology. ESA Bull 81:226-230

Davis MA, Thompson K (2001) Invasion terminology: should ecologists define their terms differently than others? No, not if we want to be of any help. ESA Bull 82:206

Feyerabend P (1993) Against method. Verso, London

Forrest B, Gross PR (2004) Creationism's Trojan horse: the wedge of intelligent design. Oxford University Press, Oxford

Foxcroft LC, Richardson DM, Wilson JRU (2008) Ornamental plants as invasive aliens: Problems and solutions in the Kruger National Park, South Africa. Environ Manage 41:32-51. doi:10.1007/s00267-007-9027-9

Hodges KE (2008) Defining the problem: terminology and progress in ecology. Front Ecol Environ 6:35-42. doi: $10.1890 / 060108$

Kuhn TS (1962) The structure of scientific revolutions. Chicago University Press, Chicago

Larson BMH (2007) An alien approach to invasive species: objectivity and society in invasion biology. Biol Invasions 9:947-956. doi:10.1007/s10530-007-9095-z

Lodge DM, Williams S, MacIsaac HJ, Hayes KR, Leung B, Reichard S et al (2006) Biological invasions: recommendations for U.S. policy and management. Ecol Appl 16:2035-2054. doi:10.1890/1051-0761(2006)016[2035: BIRFUP]2.0.CO;2

Parker IM, Simberloff D, Lonsdale WM, Goodsell K, Wonham M, Kareiva PM et al (1999) Impact: toward a framework for understanding the ecological effects of invaders. Biol Invasions 1:3-19. doi:10.1023/A:1010034312781

Pyšek P, Richardson DM, Rejmánek M, Webster GL, Williamson MK, Kirschner J (2004) Alien plants in checklists and floras: towards better communication between taxonomists and ecologists. Taxon 53:131-143. doi:10.2307/4135498

Rejmánek M, Richardson DM, Barbour MG, Crawley MJ, Hrusa GF, Moyle PB, Randall JM, Simberloff D, Williamson M (2002) Biological invasions: politics and the discontinuity of ecological terminology. ESA Bull 83: 131-133 
Ricciardi A, Cohen J (2007) The invasiveness of an introduced species does not predict its impact. Biol Invasions 9:309315. doi:10.1007/s10530-006-9034-4

Richards FJ (1959) A flexible growth function for empirical use. J Exp Bot 10:290-300. doi:10.1093/jxb/10.2.290

Richardson DM, Pyšek P, Rejmánek M, Barbour MG, Panetta FD, West CJ (2000) Naturalization and invasion of alien plants: concepts and definitions. Divers Distrib 6:93-107. doi:10.1046/j.1472-4642.2000.00083.x

Richardson DM, Pyšek P, Simberloff D, Rejmánek M, Mader AD (2008) Biological invasions - the widening debate. Prog Hum Geogr 32:295-298. doi:10.1177/0309132507 088313

Valéry L, Hervé F, Lefeuvre J-C, Simberloff D (in press) In search of a real definition of the biological invasion phenomenon itself. Biol Invasions. doi:10.1007/s10530007-9209-7

van Wilgen NJ, Richardson DM, Baard EHW (2008) Alien reptiles and amphibians in South Africa: towards a pragmatic management strategy. S Afr J Sci 104:13-20

Warren CR (2007) Perspectives on the 'alien' versus 'native' species debate: a critique of concepts, language and practice. Prog Hum Geogr 31:427-446. doi:10.1177/03091325 07079499

Williamson M (2001) Can the impacts of invasive species be predicted? In: Groves RH, Panetta FD, Virtue JG (eds) Weed risk assessment. CSIRO, Collingwood, pp 20-33 